\title{
SUJEITOS POLÍTICOS COLETIVOS E A OFENSIVA DA CONTRARREFORMA NA POLÍTICA DE SAÚDE NO MUNICÍPIO DE CAMPINA GRANDE/PB
}

\author{
Maria Joselí de Souza Silva ${ }^{1}$ \\ Gerciane da Rocha Souza Andrade ${ }^{2}$ \\ Thaísa Simplício Carneiro Matias ${ }^{3}$ \\ Alessandra Ximenes da Silva ${ }^{4}$
}

Resumo: O presente artigo analisa o processo de privatização na política de saúde, através dos "novos" modelos de gestão no município de Campina Grande/PB. Na contemporaneidade, a ofensiva social-liberal tem intensificado o processo de privatizações, implicando na perda de direitos sociais conquistados pela sociedade. O Movimento da Reforma Sanitária Brasileira busca assegurar a saúde como direito de todos e dever do Estado, bem como um Sistema Único de Saúde público estatal e de qualidade. Nesse sentido, os sujeitos coletivos se articulam no Fórum em Defesa do SUS de Campina Grande e disseminam uma cultura de resistência a toda forma de privatização da saúde.

Palavras-chave: Reforma sanitária brasileira; Sujeitos coletivos; Novos modelos de gestão; Forum em defesa do SUS.

\footnotetext{
${ }^{1}$ Serviço Social/Universidade Estadual da Paraíba, Brasil. E-mail: mjdessilva@gmail.com.

2 Serviço Social/Universidade Estadual da Paraíba, Brasil. E-mail: gerciane.souza.andrade@gmail.com.

${ }^{3}$ Serviço Social/Universidade Estadual da Paraíba, Brasil. E-mail: thaisasimplicio@hotmail.com.

${ }^{4}$ Serviço Social/Universidade Estadual da Paraíba, Brasil. E-mail: alesximenes@uol.com.br.
} 